\title{
Graphene-based hybrid materials and their applications in energy storage and conversion
}

\author{
ZHOU Ding ${ }^{1,2}$, CUI Yi ${ }^{1,2} \&$ HAN BaoHang ${ }^{1,2^{*}}$ \\ ${ }^{1}$ National Center for Nanoscience and Technology, Beijing 100190, China; \\ ${ }^{2}$ State Key Laboratory of Transducer Technology, Chinese Academy of Sciences, Shanghai 200050, China
}

Received March 23, 2012; accepted May 7, 2012

\begin{abstract}
Graphene attracts more and more scientists and researchers owing to its superior electronic, thermal, and mechanical properties. For material scientists, graphene is a kind of versatile building blocks, and considerable progress has been made in recent years. Graphene-based hybrid materials have been prepared by incorporating inorganic species and/or cross-linking of organic species through covalent and/or noncovalent interactions. The graphene-based hybrid materials show improved or excellent performance in various fields. In this review, we summarize the synthesis of graphene and graphene-based hybrid materials, and their applications in energy storage and conversion.
\end{abstract}

graphene, hybrid material, energy storage, energy conversion

Citation: Zhou D, Cui Y, Han B H. Graphene-based hybrid materials and their applications in energy storage and conversion. Chin Sci Bull, 2012, 57: 2983-2994, doi: 10.1007/s11434-012-5314-9

Graphene is a kind of two-dimensional (2D) carbon nanomaterials, and possesses a large theoretical specific surface area of about $2600 \mathrm{~m}^{2} \mathrm{~g}^{-1}$, superior electronic and thermal properties. Since its experimental realization in 2004, graphene became a famous star for the scientists in various fields, therefore, graphene-based materials and devices have been widely investigated [1]. In the material view, graphene has been considered as a kind of versatile and unique building blocks for functional materials [2]. Graphene-based hybrid materials have been fabricated by the cross-linking of graphene or graphene oxide (GO) through various kinds of inorganic or organic species, i.e. inorganic nanoparticles, polymers, multifunctional organic molecules, and metal ions/ complexes [3]. The graphene-based inorganic or organic hybrid materials have been extensively investigated in various energy storage and/or conversion related fields [4].

\section{Synthesis and modification of graphene}

The synthesis of graphene is still a bottleneck for the com-

*Corresponding author (email: hanbh@nanoctr.cn) mercial application of graphene-based materials and devices. Various methods have been developed to prepare graphene so far, which can be divided into chemical vapor deposition of graphene layers, micromechanical exfoliation of graphite using peel-off method with Scotch-tape, epitaxial growth of graphene films, bottom-up synthesis of graphene from organic molecules, and reduction/deoxygenation of GO sheets [5]. In these methods, reduction of GO is a most common method to obtain graphene with high-volume production, which can be achieved through chemical, thermal, or electrochemical reduction pathways [5]. A wide variety of reductants, such as hydrazine, sodium borohydride, hydroquinone, and aqueous alkaline solution have been used to reduce GO [6]. Meanwhile, the oxygen-containing groups could be easily removed by chemical, electrochemical or thermal methods, however, after the removal of oxygencontaining groups of GO, graphene sheets suffer from very limited dispersibility and even irreversible agglomeration due to the increase in the $\pi-\pi$ stacking interaction and van der Waals forces between graphene sheets [5]. Therefore, modification and/or stabilization of graphene are needed, which have been realized through covalent or noncovalent 
modification [5-7].

There are many oxygen-containing groups on the surface and edges of GO sheets, which make it easier to be covalent and noncovalent modified [6,7]. The most popular method for the modification of graphene and fabrication of graphene-based materials is noncovalent modification of graphene or GO sheets through different interactions, i.e. $\pi-\pi$, hydrophobic, electrostatic and chemisorption interaction. Many kinds of stabilizer have so far been employed, such as polyelectrolyte [8], pyrene derivative [9] and amphiphilic polymers [10]. Meanwhile, the oxygen containing groups, which could react with many groups, such as amido, hydroxyl, and isocyanato groups, provide a wide variety of reactions for covalent modification of graphene $[11,12]$. Furthermore, covalent surface functionalization of graphene could be realized through diazonium and azide reaction with the $\mathrm{C}=\mathrm{C}$ bond of graphene $[7,13]$. On the basis of the modification methods, graphene-based hybrid materials have prepared by incorporating and crosslinking graphene or GO by the multifunctional inorganic or organic crosslinkers.

\section{Preparation of graphene-based hybrid mate- rials}

Various kinds of graphene-based hybrid materials have been fabricated through the crosslinking or assembling of graphene or GO sheets by covalent or noncovalent methods [14-16]. According to the crosslinker used in the fabrication of graphene-based hybrid materials, they could be divided into two catalogs: graphene-based inorganic materials and graphene-based organic materials. Graphene-based inorganic hybrid materials are fabricated by incorporating inorganic species between graphene sheets, such as inorganic nanostructures and metal ions; while for graphene-based organic hybrid materials, organic molecules are used as crosslinkers through noncovalent and covalent interactions.

\subsection{Graphene-based inorganic materials}

Inorganic materials, such as metal and metal oxides showed wide applications in electrode materials and catalysis $[2,4]$. In recent years, various kinds of graphene-inorganic hybrid materials were fabricated by incorporating the inorganic nanostructure between graphene sheets through the driving force of chemisorption interaction. The methods for the synthesis of graphene-based inorganic hybrid materials could be classified into two categories: (i) assembly of graphene (oxides) with synthesized inorganic nanostructures, and (ii) one-pot synthesis and assembly of graphene and inorganic nanostructures. In the first method, inorganic nanostructures are prepared and then mixed with graphene or GO dispersion. However, in the second method, graphene and inorganic species are obtained in situ and then assemble together in one-pot reaction.
Several groups have extensively investigated the second strategy, i.e. metal or metal oxide nanoparticles are mixed with GO or graphene dispersion to fabricate functional materials. $\mathrm{SnO}_{2}$-graphene was prepared through assembling of graphene sheets and $\mathrm{SnO}_{2}$ nanoparticles in ethylene glycol to fabricate porous electrode materials with delaminated structure [17]. Scheuermann et al. [18] synthesized palladium nanoparticle-graphene composite and investigated its catalytic activity in Suzuki-Miyaura coupling reaction. $\mathrm{Pd}^{2+}$ was immobilized on GO sheets by ion exchange method, and then the obtained GO-Pd ${ }^{2+}$ precursor was reduced through thermal expansion, hydrogen, or hydrazine reduction. Polyoxometalate (POM) nanoparticles are incorporated between graphene sheets by reduction of the mixture of GO and POM. GO and POM are both negatively charged, therefore, the mixture are homogeneous without aggregation. After the addition of hydrazine into the mixture, GO was reduced into graphene, which assembled with POM through the driving force of chemisorption interaction into three-dimensional (3D) porous structures [19].

On the basis of the chemical routes developed for the preparation of graphene and inorganic materials, various kinds of graphene inorganic hybrid materials with unique performances are designed and fabricated. Besides metals, metal oxides, graphene-based hybrid materials containing different inorganic species, such as metal nitride [20], and metal sulfide [21], metal selenide [22], metal telluride [23], metal antimonide [24], and multi-element compounds have been prepared for the application in the energy storage and conversion materials. Hydro- or solvo-thermal process is a simple method for the preparation of graphene-based inorganic materials [4,25], in which GO could be reduced into graphene and the metal ions precursors would be transformed into metal or metal oxide species, therefore, the inorganic species could be incorporated into the graphene matrix. Novel metal and metal oxide nanoparticles promoted assembly of graphene with low density and tunable macro and microstructures are achieved successfully by using a hydrothermal method [26]. In a solvothermal reaction, graphene-CdS composite material with good structural and optoelectronic properties has been successfully and directly synthesized from the mixture of $\mathrm{GO}$ and $\mathrm{Cd}^{2+}$ in the solvent of DMSO [21] (Figure 1).

Further thermal treatment of graphene-metal oxide composites could also result in other kinds of graphene-based materials. $\mathrm{GO}-\mathrm{V}_{2} \mathrm{O}_{5}$ was synthesized through a sol-gel method, and was thermally annealed at $800^{\circ} \mathrm{C}$ in the atmosphere of ammonia. In the thermal annealing process, $\mathrm{V}_{2} \mathrm{O}_{5}$ transformed into vanadium nitride and GO was reduced and $\mathrm{N}$-doped, therefore $\mathrm{N}$-doped graphene-vanadium nitride (GVN) composite could be obtained [20]. Furthermore, when thermally treated in $\mathrm{H}_{2} \mathrm{~S}$ or $\mathrm{H}_{2}$, the metal oxides would be transformed into metal sulfide or reduced into metal. In this way, graphene-metal sulfide or graphenemetal hybrid materials could be obtained [4]. 


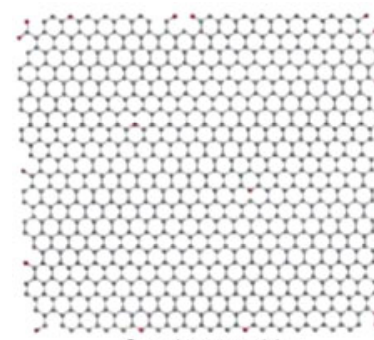

Graphene oxide
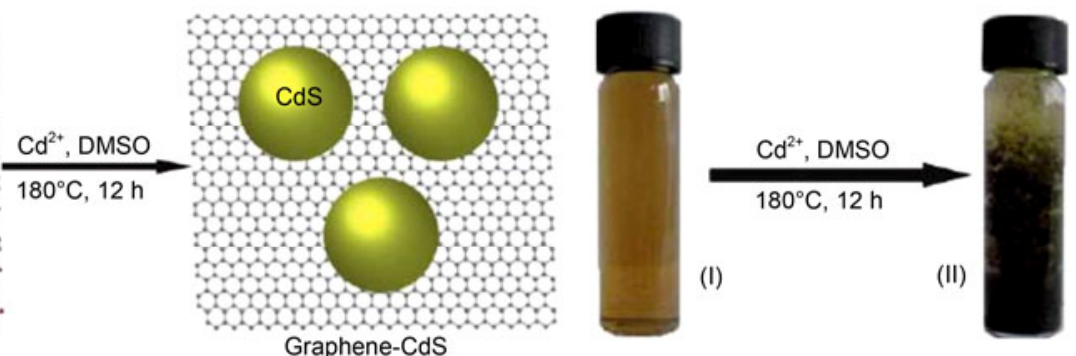

Figure 1 (Color online) Solvothermal synthesis of graphene-CdS hybrid material. Reprinted from ref. [21] with permission from the Wiley-VCH.

\subsection{Graphene-based organic materials}

Graphene-based organic materials have been constructed through covalent linkage and noncovalent crosslinking of the graphene or GO sheets. For the covalent linking method, bi- or multi-functional molecules are used as crosslinkers, in which the functional groups could react with the oxygencontaining groups and the carbon skeletons. For the noncovalent crosslinking method, the interactions between GO and polymers, i.e. hydrogen bonding, $\pi-\pi$ stacking, hydrophobic interaction, electrostatic interaction, and chemisorption, perform as the driving forces for the formation of the graphene-based organic hybrid materials [6,7].

Graphite oxide hybrid porous materials (GHPMs) were prepared through the crosslinking of GO sheets with organic diisocyanates by using the reaction of diisocyanate with the carboxyl and hydroxyl groups on both sides of the sheets (Figure 2). The obtained graphite oxide hybrid porous materials exhibit a much enhanced porosity $\left(168 \mathrm{~m}^{2} \mathrm{~g}^{-1}\right)$ compared with the powdery GO [27].

This versatile functionalization of graphene with organic molecules allows it to act as building blocks in designing metal-organic framework (MOF) hybrids or other porous materials. MOF nanowire on benzoic acid-functionalized graphene was fabricated as shown in Figure 3. The hybrid material possesses a specific surface area of $810 \mathrm{~m}^{2} \mathrm{~g}^{-1}$ [28].

Besides the increase in the porosity, the crosslinking would also enhance the mechanical and thermal stability of the hybrid material. GO paper is exposed in the glutaraldehyde (GA) vapor to prepare GA crosslinked GO paper. As a consequence of better interlayer adhesions, the mechanical property of the GA-treated GO paper has an average modulus of about $30.4 \mathrm{GPa}$ and strength of about $101 \mathrm{MPa}$, which are about $190 \%$ and $60 \%$ higher than that of the as-received GO paper [29]. $\mathrm{Zu}$ et al. [30] employ triblock copolymers (PEO- $b$-PPO- $b$-PEO) as the stabilizer for chemically exfoliated graphene oxide, and supramolecular hydrogel are formed with $\alpha$-cyclodextrins through the penetration of PEO chains into the cyclodextrin cavities (Figure 4).

\section{Application of graphene-based hybrid materials}

\subsection{Supercapacitor}

Owing to its high power density, long cycle life, and small size, supercapacitor is considered to be one of the most attractive and promising electrochemical energy storage systems [31]. In general, there are two kinds of energy storage mechanisms for supercapacitor: (i) electrical double-layer capacitance and (ii) pseudocapacitance. Carbon material is a kind of electrical double-layer capacitor and widely used as electrode materials for supercapacitor because of its good stability and low cost $[32,33]$. Pseudocapacitor electrode materials, like conducting polymers and transition metal oxides, exhibit a higher capacitance due to the reversible Faradic redox reaction. Hybridization of the two kinds of capacitor material would possibly obtain a synergistic effect, which would result in an increase in the performance of the hybrid capacitor. In order to improve the electrochemical performance, many attempts have been devoted to the hybridization of different components and optimization of the nanostructures [34].

Graphene synthesized by different methods has been investigated as the electrode materials for supercapacitor, and it exhibits a good stability and a specific capacitance of about 100-264 $\mathrm{F} \mathrm{g}^{-1}[4,33]$. Introducing functional species into graphene matrix could improve the electrochemical stability and rate performances. Graphene-based organic hybrid materials containing conducting polymers, such as polyaniline (PANI), polypyrrole, and poly(ethylenedioxythiophene) (PEDOT), exhibit a specific capacitance of about 300-1500 $\mathrm{F} \mathrm{g}^{-1}$ [35-37]. Graphene-PANI composite film prepared by filtration of the mixture of graphene and PANI showed a specific capacitance of about $210 \mathrm{~F} \mathrm{~g}^{-1}$ [35]. Morphology-controlled synthesis of functional species on GO or graphene sheets would also increase the electrochemical performances. Through the in situ polymerization method, PANI nanowire arrays have been uniformly aligned on GO sheets (Figure 5(A)). The specific capacitance of the PANI-GO composites can reach as high as $555 \mathrm{~F} \mathrm{~g}^{-1}$ at a discharge current density of $0.2 \mathrm{~A} \mathrm{~g}^{-1}$ (Figure 5(B)). Meanwhile, owing to the synergistic effect of GO and PANI nanowire, the capacitance retention of PANI-GO nanocomposite still kept $92 \%$ of its initial capacitance (Figure $5(\mathrm{C})$ ), while pristine PANI kept only $74 \%$ of its initial capacitance $[36,38]$.

In the meanwhile, many efforts have been put into the fabrication of graphene-metal oxides hybrid materials. Transition metal oxides, especially, ruthenium oxide $\left(\mathrm{RuO}_{2}\right)$ and 

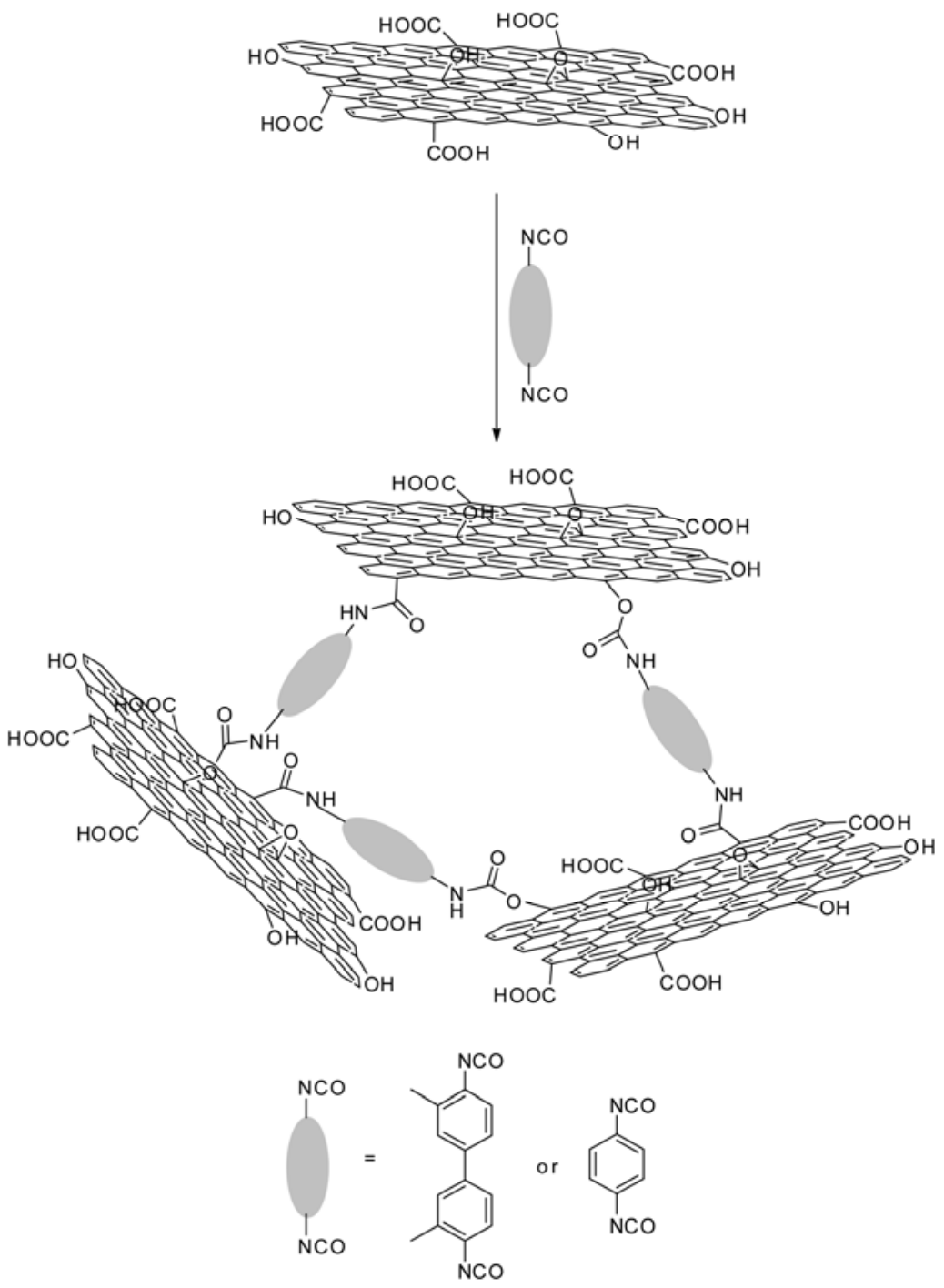

Figure 2 Scheme of the construction of GHPMs through crosslinking GO sheets with organic diisocyanates. Reprinted from ref. [27] with permission from the Elseier B.V.

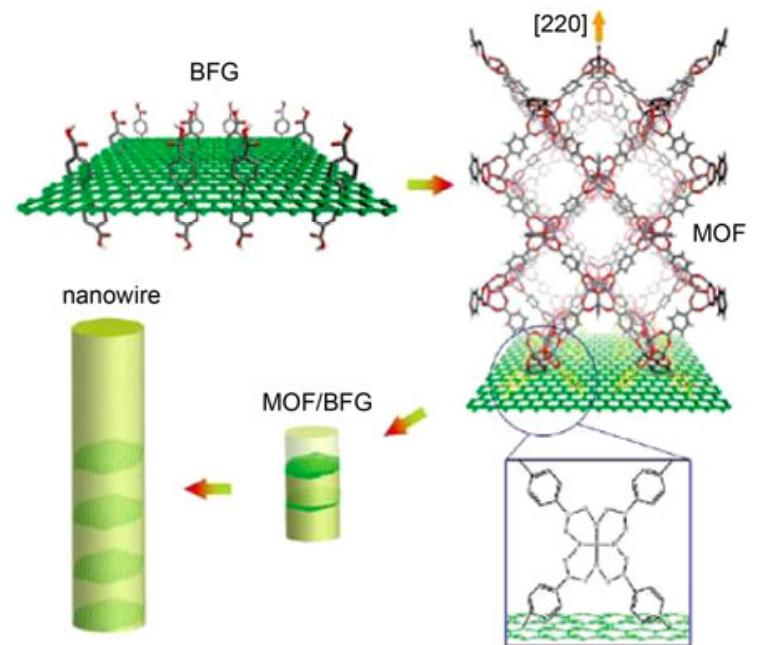

Figure 3 (Color online) Schematic of proposed bonding between functionalized graphene and MOF via - $\mathrm{COOH}$ groups. Reprinted from ref. [28] with permission from the American Chemical Society. manganese oxide $\left(\mathrm{MnO}_{2}\right)$, are considered as the most promising materials offering a high specific capacitance with an excellent cyclability $[32,33]$. Graphene- $\mathrm{RuO}_{2}$ hybrid materials reported by Cheng's group $[39,40]$ showed an excellent electrochemical stability (97.9\% retention after 1000 cycles). The specific capacitance of graphene- $\mathrm{MnO}_{2}$ composites could reach up to $300 \mathrm{~F} \mathrm{~g}^{-1}$ [41]. Up to date, the largest specific capacitance of graphene-based inorganic material is reported by Dai's group [42] for the graphene$\mathrm{Ni}(\mathrm{OH})_{2}$, in which $\mathrm{Ni}(\mathrm{OH})_{2}$ hexagonal nanoplates were grown on low-oxidation graphene sheets (Figure 6(a)). The specific capacitance of the graphene- $\mathrm{Ni}(\mathrm{OH})_{2}$ hybrid material is about $1335 \mathrm{~F} \mathrm{~g} \mathrm{~g}^{-1}$ and is comparable to the graphene-conducting polymer hybrid materials. The high specific capacitance and remarkable rate capability are promising for the applications in supercapacitors with both high energy and power densities (Figure 6(b) and (c)).

The performance of graphene-based supercapacitor could 

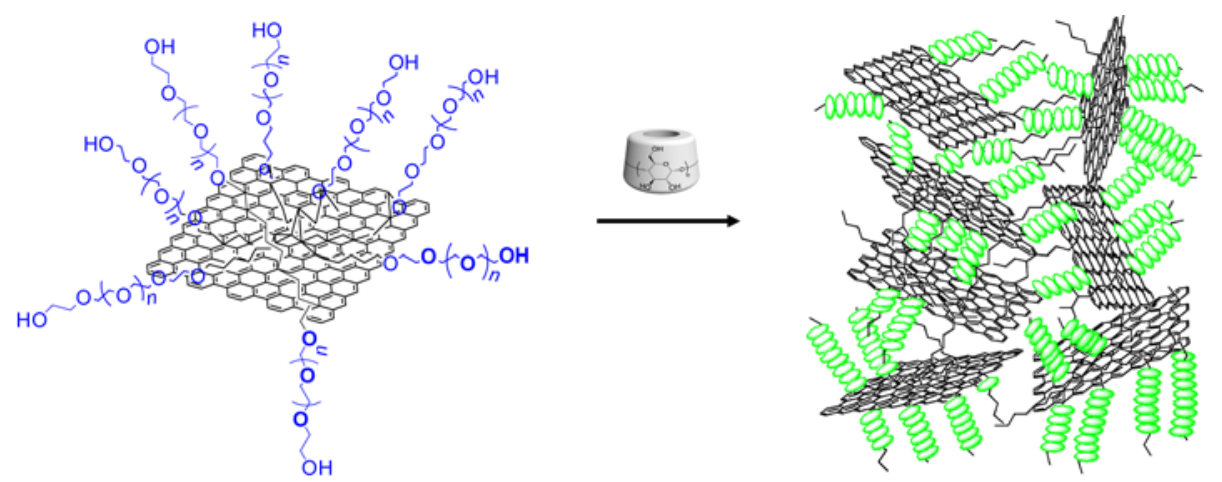

Figure 4 (Color online) Proposed structure of the copolymer coated graphene and the formation of the supramolecular hybrid hydrogel. Reprinted from ref. [30] with permission from the American Chemical Society.

(A)

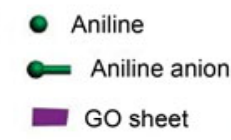

(a)

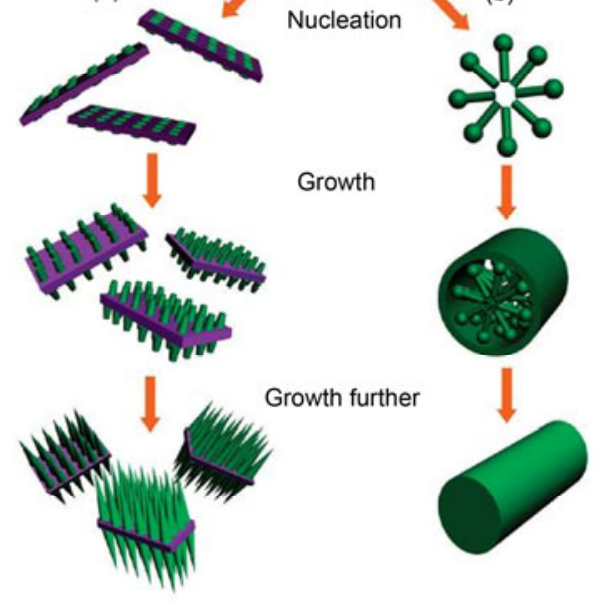

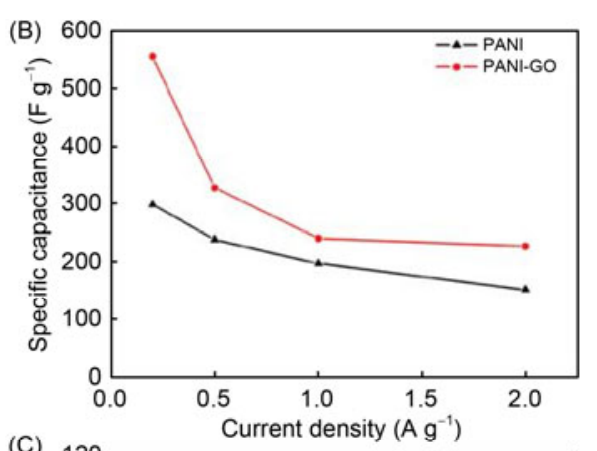

(C)

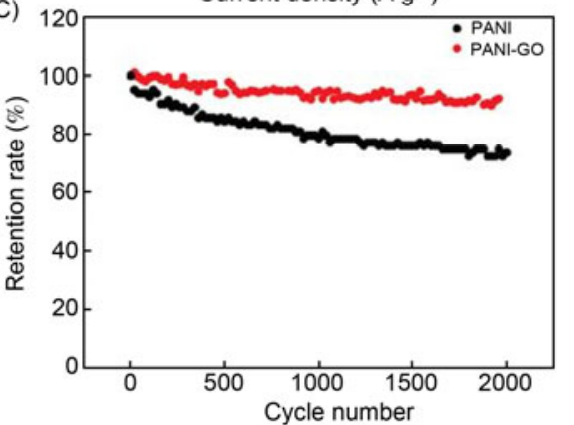

Figure 5 (Color online) (A) Schematic illustration of nucleation and growth mechanism of PANI nanowires: (a) heterogeneous nucleation on GO nanosheets; (b) homogeneous nucleation in bulk solution. (B) Specific capacitance of PANI and PANI-GO at different current densities. (C) Stability of PANI and PANI-GO. Reprinted from ref. [36] with permission from the American Chemical Society.

(a)

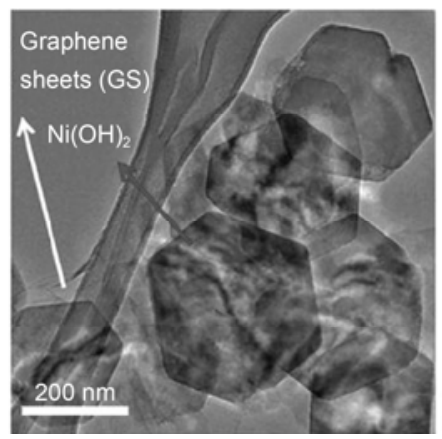

(b)

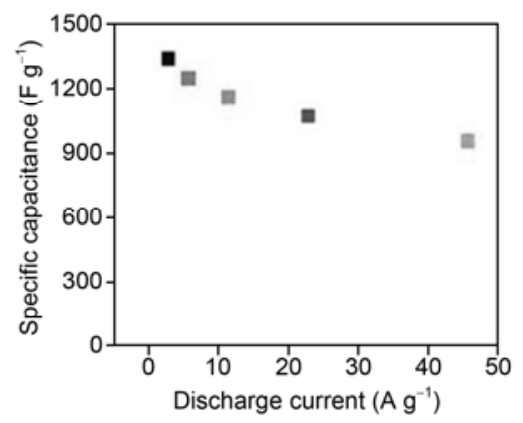

(c)

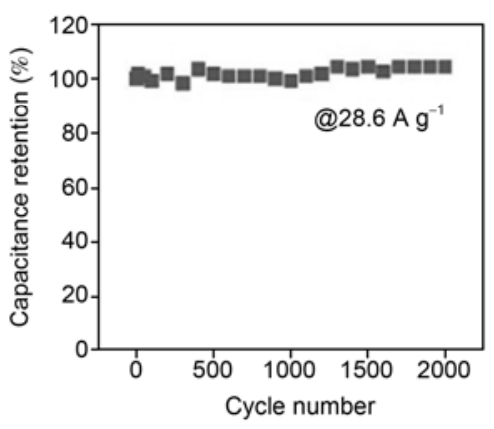

Figure 6 TEM image (a), specific capacitance (b), and capacitance retention (c) of graphene-Ni(OH) 2 . Reprinted from ref. [42] with permission from the American Chemical Society.

be improved by increasing its electrical double-layer capacitance and pseudocapacitance. For electrical double-layer capacitance, one effective method is to increase the surface area and optimize the porosity in the materials. Whereas, introducing of functional species with redox ability would increase the pseudocapacitance and even produce synergistic 
benefits on the performance.

\subsection{Lithium ion battery}

Lithium ion battery (LIB) is an electrochemical energy storage device based on intercalation and deintercalation of lithium ions, and generally fabricated by an anode, cathode electrode, and electrolyte (separator) [43]. The performance of lithium ion batteries is largely depending on the physical and chemical properties of the cathode and anode materials [44]. Metals, (lithium containing) metal oxide and carbon materials are widely investigated as LIB electrode materials $[32,33]$. Graphene or graphene-based materials were investigated as electrode materials in recent years [45,46]. The lithium storage properties of graphene were investigated by Yoo et al. [47], and it shows higher capacity (about $540 \mathrm{~mA} \mathrm{~h}$ $\mathrm{g}^{-1}$ ) than that of graphite (about $372 \mathrm{~mA} \mathrm{~h} \mathrm{~g}^{-1}$ ). After incorporating CNT and $\mathrm{C}_{60}$ between graphene sheets, the capacities increase up to 730 and $784 \mathrm{~mA} \mathrm{~h} \mathrm{~g}^{-1}$, respectively.

Graphene would increase the performance of the LIB electrode from two aspects, one is the capacitance and the other one is stability. Graphene- $\mathrm{SnO}_{2}$ hybrid material is firstly reported by Honma's group [17] and it was then investigated as the LIB anode material. The obtained graphene- $\mathrm{SnO}_{2}$ exhibits a reversible capacity of $810 \mathrm{~mA} \mathrm{~h} \mathrm{~g}^{-1}$, while that of the bare $\mathrm{SnO}_{2}$ nanoparticle on the first charge was $550 \mathrm{~mA} \mathrm{~h} \mathrm{~g}^{-1}$. Furthermore, the cycling performance also improved, the charge capacity of graphene- $\mathrm{SnO}_{2}$ still remained $70 \%\left(570 \mathrm{~mA} \mathrm{~h} \mathrm{~g}^{-1}\right)$ of the reversible capacity after 30 cycles, in comparison, bare $\mathrm{SnO}_{2}$ nanoparticle decreased dramatically from $550 \mathrm{~mA} \mathrm{~h} \mathrm{~g}^{-1}$ on the first charge to $60 \mathrm{~mA} \mathrm{~h} \mathrm{~g}^{-1}$ only after 15 cycles (Figure 7).

Lithium containing metal oxides (i.e. $\mathrm{LiFePO}_{4}, \mathrm{LiMn}_{2} \mathrm{O}_{4}$ ) are widely used as cathode materials for LIB, but the main limitation for applications is their poor conductivity and lithium ion diffusion. In order to solve this problem, doping with foreign atoms, decreasing the particle size, and coating with electronically conductive materials are three common pathways $[43,44]$. Inspired by the excellent conductivity and large theoretical surface area of graphene, $\mathrm{LiFeO}_{4}$ nanoparticles are modified on graphene sheets. The capacity and cycle performances of $\mathrm{LiFePO}_{4}$ could be improved considerably by the addition of graphene, and the hybrid cathode possesses an initial discharge capacity of $160 \mathrm{~mA} \mathrm{~h} \mathrm{~g}^{-1}$ at $0.2 \mathrm{C}$ and the capacity retained $110 \mathrm{~mA} \mathrm{~h} \mathrm{~g}^{-1}$ even at high rate of $10 \mathrm{C}$ with only $1.5 \mathrm{wt} \%$ of graphene [48].

Nanostructured composites can often produce synergistic benefits on the performance of the LIB electrode materials $[32,33]$. Graphene-PEDOT- $\mathrm{MnO}_{2}$ composites with hierarchically nanostructure are fabricated by combining onedimensional (1D) rod-like $\mathrm{MnO}_{2}$ and 2D graphene nanosheet. PEDOT was grown on graphene matrix by in-situ polymerization, and the $1 \mathrm{D}$ rod-like $\mathrm{MnO}_{2}$ was then grown on the graphene-PEDOT composites (Figure 8(b)). Owing to the high specific surface area, redox ability of the conjugating polymer and $\mathrm{MnO}_{2}$, and good conductivity, graphene-PEDOT$\mathrm{MnO}_{2}$ composite shows a significantly improved performance and stability. Graphene-PEDOT- $\mathrm{MnO}_{2}$ exhibits a large first discharge capacity of $1835 \mathrm{~mA} \mathrm{~h} \mathrm{~g}^{-1}$ and retains $948 \mathrm{~mA} \mathrm{~h} \mathrm{~g}^{-1}$ after 15 cycles; while for graphene- $\mathrm{MnO}_{2}$, the capacity is about $1180 \mathrm{~mA} \mathrm{~h} \mathrm{~g}^{-1}$ at the first cycle and decreases to $421 \mathrm{~mA} \mathrm{~h} \mathrm{~g}^{-1}$ after 15 cycles [49] (Figure 8(a)).

Porosity is an important factor influencing the performance of the electrode materials. Graphene provides a large surface area for the deposition or growth of functional species, which would optimize the porosity of the hybrid materials. The porosity would also increase the flow of electrolyte, which is beneficial for the charging and discharging of the battery system. Meanwhile, the electron interactions between the components and graphene would also have an impact on the electrochemical performances.

\subsection{Hydrogen storage}

Hydrogen storage is one of the main issues for the realization of fuel cell powered vehicles using hydrogen as the energy carrier, and carbon based nanomaterials are the ideal media for hydrogen storage due to their highly porous
(A)

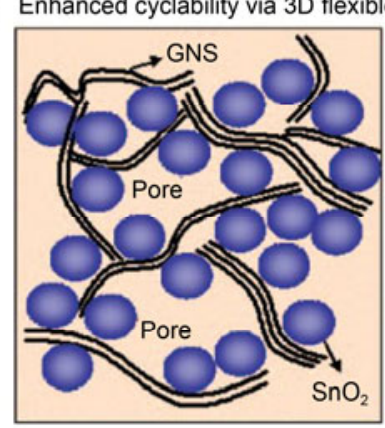

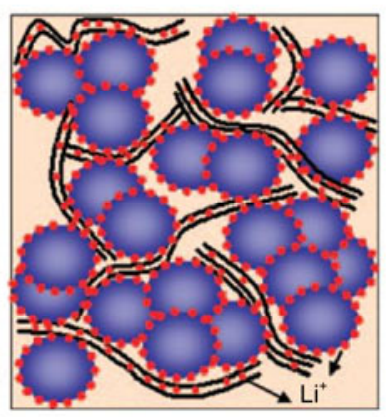

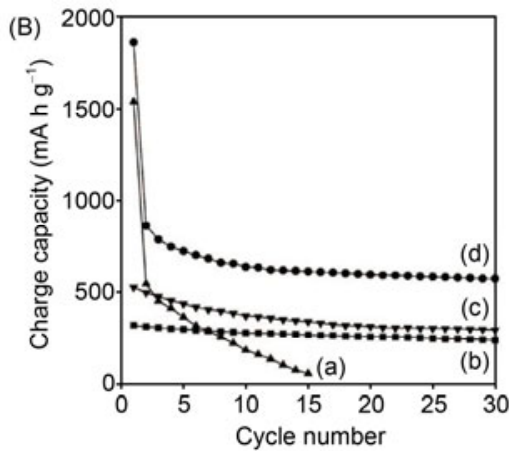

Figure 7 (Color online) (A) Scheme of the insertion and extraction of the $\mathrm{Li}^{+}$ions in the graphene-SnO $\mathrm{O}_{2}$, and $(\mathrm{B})$ the cyclic performances for (a) bare $\mathrm{SnO} 2$ nanoparticle, (b) graphite, (c) graphene, and (d) graphene- $\mathrm{SnO}_{2}$ composites. Reprinted from ref. [17] with permission from the American Chemical Society. 

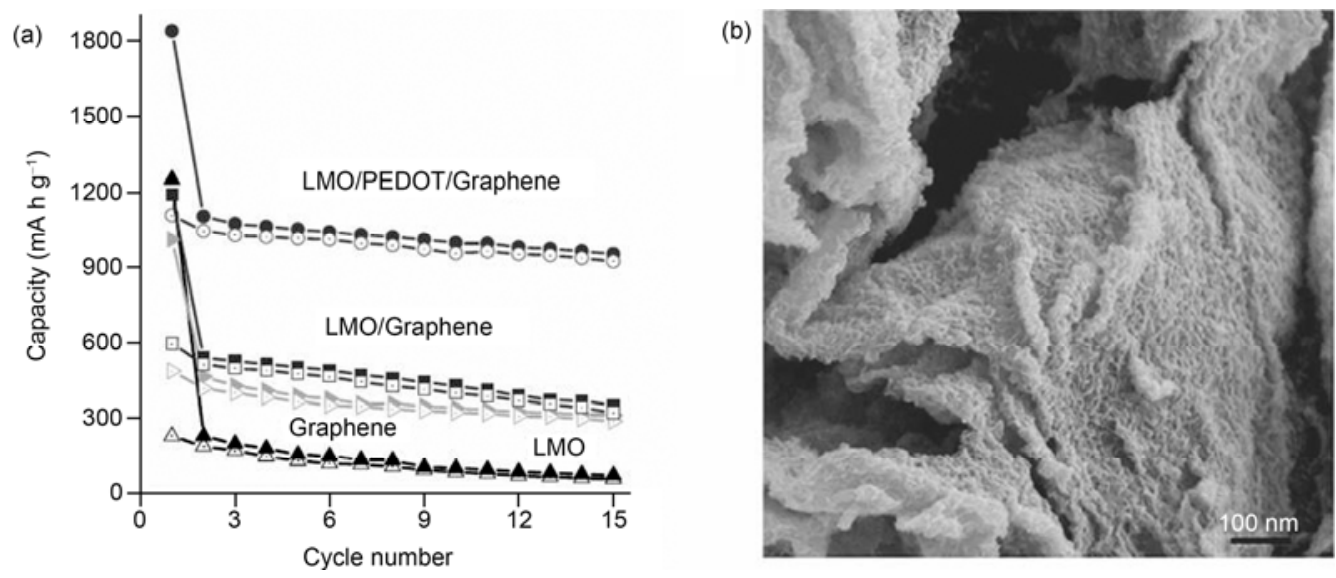

Figure 8 Cyclic performance (a) and SEM image (b) of graphene-PEDOT- $\mathrm{MnO}_{2}$. Reprinted from ref. [49] with permission from the Wiley-VCH.

structure, low density, high stability, and large surface area. Porous graphene materials are theoretically investigated as gas separation membrane [50] or hydrogen purification membrane [51,52]. Meanwhile, in the study of graphenebased porous material, gas sorption and separation properties are investigated. Owing to the large theoretic surface area and the 2D structure of graphene, graphene-based porous materials are fabricated by incorporating inorganic nanoparticles and crosslinking of bifunctional material. The attempts focus on increasing the surface area, optimizing the porosity and doping of other atoms or ions [4].

Inorganic nanoparticles are using as the spacer to increase the distance between graphene sheets in order to construct 3D graphene structure with high porosity. As shown in Figure 9, POM nanoparticles are incorporated between graphene sheets to prepare graphene-POM (GPOM), which was then oxided into o-GPOM due to the redox ability of the POM. Owing to the changes in micropores and electron distribution, the hydrogen uptake increases from $0.8 \mathrm{wt} \%$ of GPOM to $1.3 \mathrm{wt} \%$ of o-GPOM. Inspired by the redox ability of POM, controllable hydrogen adsorptiondesorption ability could be achieved by tuning the redox state of POM [19].

Although the space between graphene sheets could be increased by the inorganic nanoparticles, but the specific surface area values are usually lower than the reduced-GO owing to the large density of the inorganic nanoparticles [53]. Rigid bifunctional molecules would also serve as the crosslinker through covalent binding. The graphene-based organic hybrid materials possess lower density, which is beneficial for obtaining larger specific surface area. Srinivas et al. [54] synthesized the porous GO frameworks (GOFs) by expansion of GO sheets with various linear boronic acid pillaring units in a solvothermal reaction. The GOF structures develop through boronate-ester formation as a result of $\mathrm{B}-\mathrm{O}$ bonding between boronic acids and oxygen functional groups on the GO layers. The obtained frameworks possess a specific surface area of $470 \mathrm{~m}^{2} \mathrm{~g}^{-1}$ and $\mathrm{H}_{2}$ uptake capacities of $1.2 \mathrm{wt} \%$ at $10.0 \mathrm{bar}\left(1 \mathrm{bar}=10^{5} \mathrm{~Pa}\right)$, and $77 \mathrm{~K}$.

\subsection{Solar cells}

Graphene is considered as a promising next-generation conducting material and possible to replace the indium tin oxide
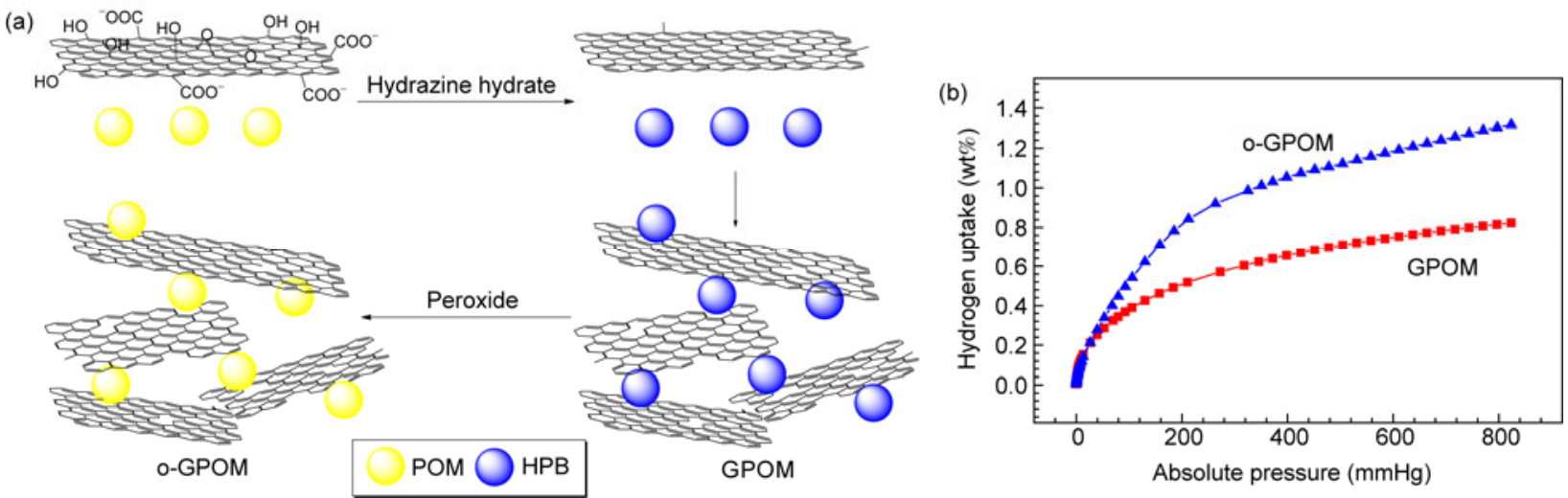

Figure 9 (Color online) Scheme of the formation process (a) and the hydrogen uptake isotherms (b) of GPOM and o-GPOM. $1 \mathrm{mmHg}=1.33 \times 10^{2} \mathrm{~Pa}$. Reprinted from ref. [19] with permission from the Wiley-VCH. 
and fluorine tin oxide in optoelectronic devices owing to its high electron mobility, high thermal stability, and flexibility [4,5]. Graphene films are fabricated because of the solution processable operation of (functionalized) graphene sheets, such as the spinning coating methods [55,56].

The most important reason for graphene-based materials being used as electrode materials in the organic photovoltaic devices is the high electron mobility of graphene, which increases the charge separation and hole transportation in the organic photovoltaic devices. Graphene was incorporated into $\mathrm{TiO}_{2}$ nanostructure anode in dye-sensitized solar cells (DSSCs). In the hybrid anode, graphene could be considered as a bridge for the photoelectrons, thus enhances the charge transport rate and prevents the charge recombination. Meanwhile, the light collection efficiency of the hybrid anode also increased, therefore, the photoelectrical conversion efficiency is improved [57] (Figure 10).

Vertically aligned carbon nanotubes (VACNTs) are growing directly onto a freestanding graphene paper by using chemical vapor deposition method, and the composite paper was then investigated as the counter electrode of the DSSCs. Owing to the VACNTs growing on the graphene paper could provide the shortest transportation paths for the electrons, the composite paper exhibits an improved conversion efficiency as the counter electrode of about $6.05 \%$, which is about $83 \%$ of that with a Pt film electrode [58].

Functionalized graphene material have been investigated as electron-accepter material in the bulk heterojunction photovoltaic devices with $\mathrm{P} 3 \mathrm{OT}$ and $\mathrm{P} 3 \mathrm{HT}$ as donor material. The interaction between graphene and P3OT/P3HT makes this composite work well as the active layer in bulk heterojunction-organic photovoltaic devices and the best power conversion efficiency of could be obtained at $1.4 \%$ under sun light illumination from a filtered Xenon lamp [55] (Figure 11).

\subsection{Fuel cells}

Catalyst shows a crucial effect on both the cost and durability of fuel cells. In order to improve the catalytic efficiency, a

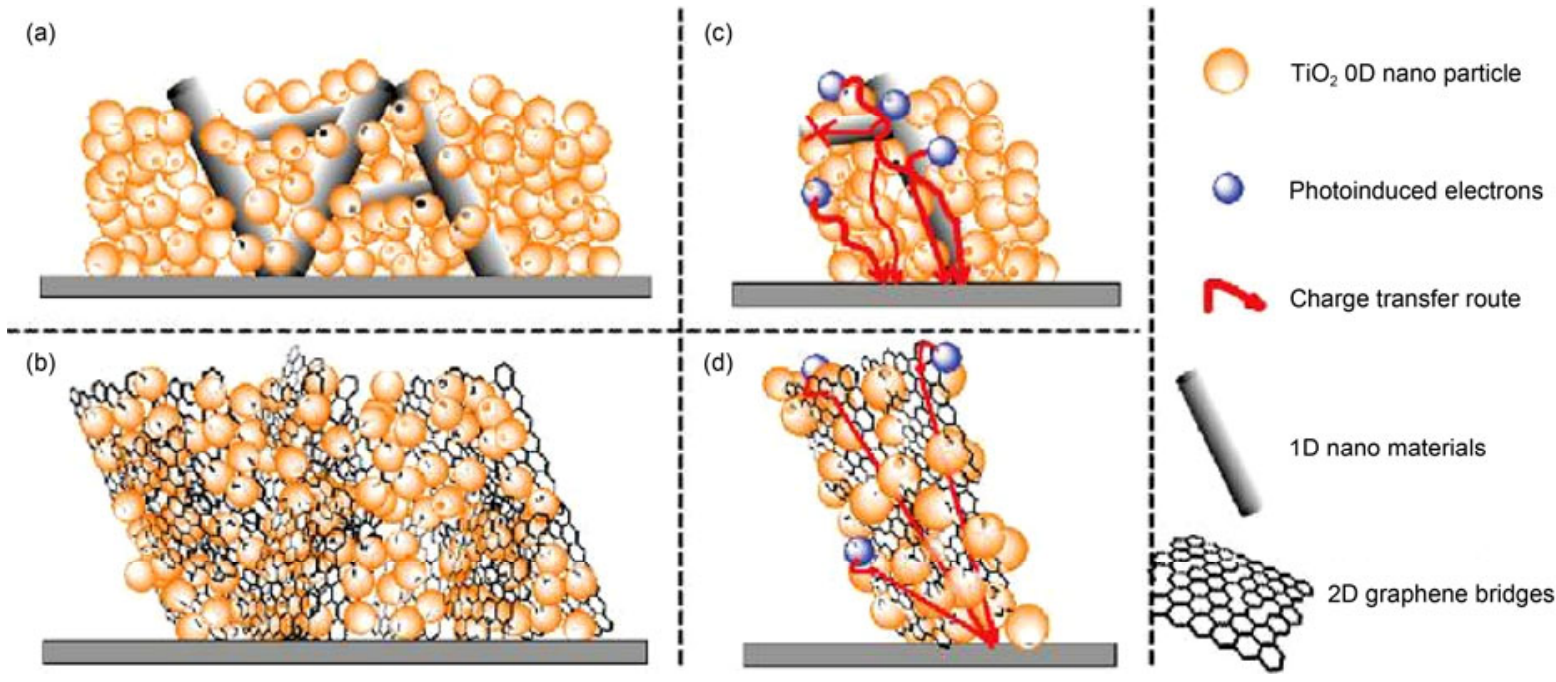

Figure 10 (Color online) Scheme of the improved electron bridge effect of the graphene- $\mathrm{TiO}_{2}$ electrode. Reprinted from ref. [57] with permission from the American Chemical Society.
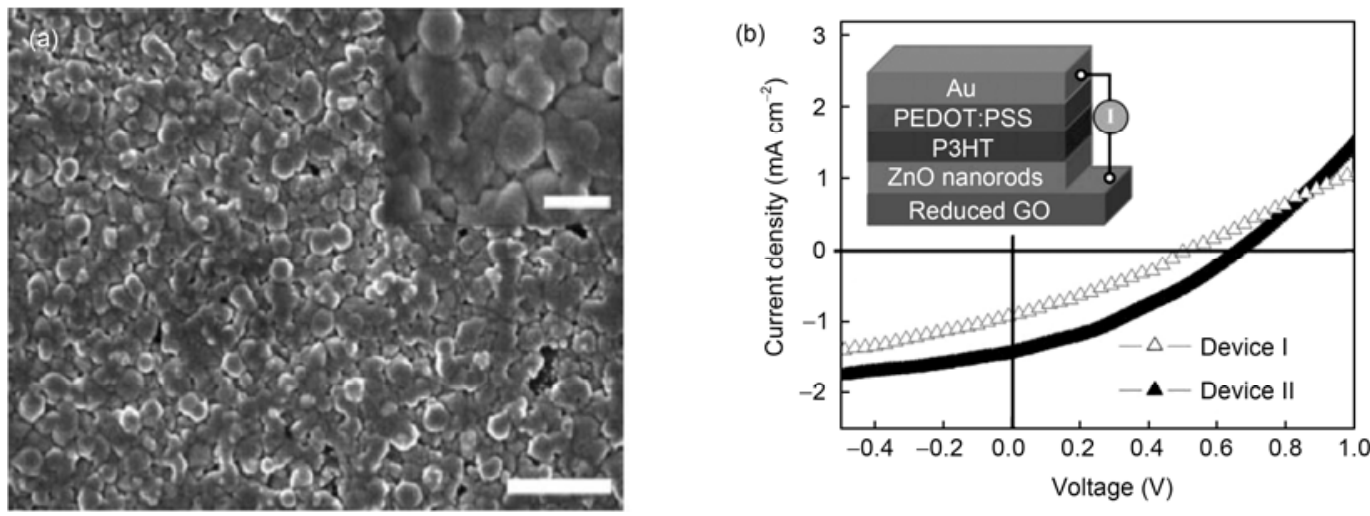

Figure 11 (a) SEM images of electrochemically deposited $\mathrm{ZnO}$ on rGO films (scale bars: images (2 mm) and inset (600 nm)), and (b) $I$ - $V$ curves for $\mathrm{ZnO} / \mathrm{P} 3 \mathrm{HT}$ hybrid solar cells under simulated globe sun illumination. Reprinted from ref. [55] with permission from the Wiley-VCH. 
carbon material is widely used as the supporting material for catalyst nanoparticles due to its high surface area and stability [4]. As a 2D structured carbon material, graphene has a large surface area and both sides of the sheets can used to support catalyst. Furthermore, due to its mechanical, structural, and electronic properties, graphene exhibits an outstanding performance as the support material for fuel cells since its discovery [59-61].

Platinum-based (Pt-based) electrocatalysts have been widely used as the electrocatalysts in direct methanol fuel cells for the respective methanol oxidation and oxygen reduction reaction. Pt nanoparticles are deposited on or incorporated between graphene sheets to fabricate graphenePt hybrid electrode for fuel cell. The hybrid electrode shows a much higher catalytic activity, better stability and tolerance toward $\mathrm{CO}$. The maximum power density of graphene/ Pt catalyst is $260 \mathrm{~mW} \mathrm{~cm}^{-2}$ at $540 \mathrm{mV}$, which is higher than that of the commercial $\mathrm{Pt} / \mathrm{C}$ catalyst $(139 \mathrm{~mW}$ $\mathrm{cm}^{-2}$ at $540 \mathrm{mV}$ ) [62]. PtRu/graphene catalyst was prepared and compared with PtRu/MWCNTs catalysts in the application in direct methanol fuel cells, in which the current value of PtRu/ graphene catalyst is about 2.5 times higher than that of the PtRu/MWCNTs catalyst. Furthermore, the $\mathrm{PtRu} / \mathrm{graphene}$ catalyst exhibits a better tolerance to poisoning species in methanol $[63,64]$.

Functionalized GO-Nafion nanocomposite has been prepared and investigated in the application of proton exchange membrane fuel cell. The addition of graphene offers substantial proton exchange membrane fuel cell performance improvements at elevated temperatures. The composite displays a peak power density of $0.042 \mathrm{~W} \mathrm{~cm}^{-2}$, and a significant proton conductivity improvement (four times) in comparison with Nafion at a low humidity value and high temperature [65].

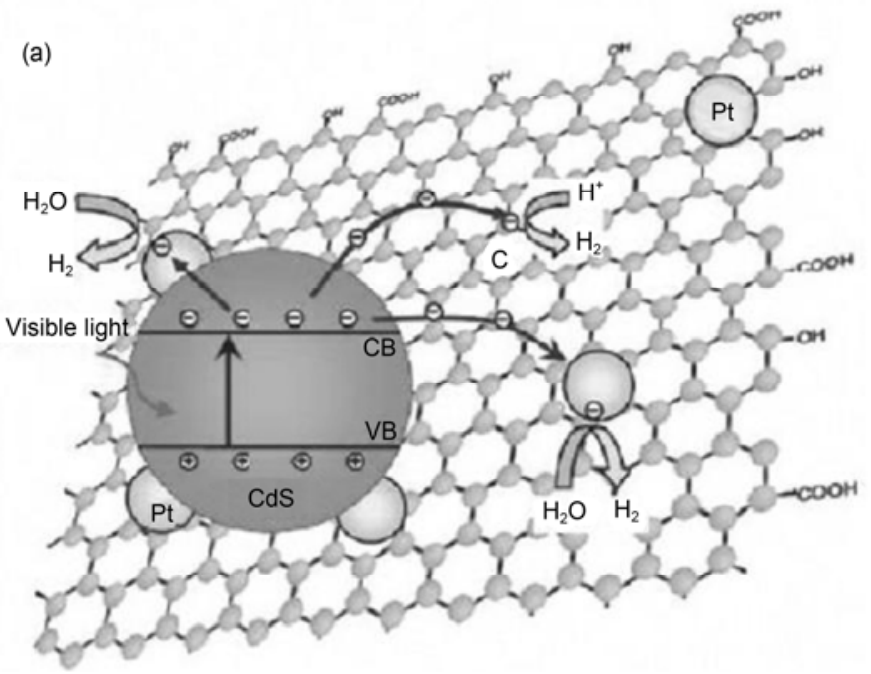

\subsection{Water splitting}

Hydrogen energy has been considered as a renewable and clean energy, which solves the future energy and environmental problems. To produce hydrogen, an ideal way is the water splitting under visible light irradiation with the assistance of photocatalyst. Semiconductor photocatalysts, such as $\mathrm{TiO}_{2}, \mathrm{CdS}$, have been developed for the photocatalytic reaction [66,67]. Graphene can create a $2 \mathrm{D}$ conductive support path for charge transport and collection, which can be used to enhance electron transport properties of semiconductor photocatalyst [68].

$\mathrm{CdS}$ clusters were decorated on graphene nanosheets through a one-step solvothermal method and were investigated as visible-light-driven photocatalysts. Graphene serves as the electron collector and transporter that efficiently lengthen the lifetime of the photogenerated charge carriers from $\mathrm{CdS}$ nanoparticles (Figure 12(a)). As a result, the graphene-CdS composite exhibits a high $\mathrm{H}_{2}$-production rate of $1.12 \mathrm{mmol}$ $\mathrm{h}^{-1}$, which is about five times higher than that of pure CdS nanoparticles. Meanwhile, its apparent quantum efficiency (QE) is $22.5 \%$ at wavelength of $420 \mathrm{~nm}$ (Figure 12(b)) [69].

Besides the traditional metal-containing semiconductor photoconductor, a metal-free polymeric photocatalyst, graphitic carbon nitride $\left(\mathrm{g}-\mathrm{C}_{3} \mathrm{~N}_{4}\right)$ has been developed in recent years [70]. Owing to its high thermal, chemical stability and interesting electronic properties, $\mathrm{g}-\mathrm{C}_{3} \mathrm{~N}_{4}$ showed a good photocatalytic performance for hydrogen or oxygen production via water splitting under visible-light irradiation. Furthermore, graphene-g- $\mathrm{C}_{3} \mathrm{~N}_{4}$ hybrid material shows high conductivity and photocatalytic properties compared to pure g- $\mathrm{C}_{3} \mathrm{~N}_{4}$. With the optimized content of graphene (sample $\mathrm{GC} 1.0,1.0 \mathrm{wt} \%$ ), the corresponding $\mathrm{H}_{2}$-production rate of graphene-g- $\mathrm{C}_{3} \mathrm{~N}_{4}$ was $451 \mu \mathrm{mol} \mathrm{h}{ }^{-1} \mathrm{~g}^{-1}$, which is more than 3.07 times of the value of pure $g-\mathrm{C}_{3} \mathrm{~N}_{4}$ (Figure 13) [71].

(b)

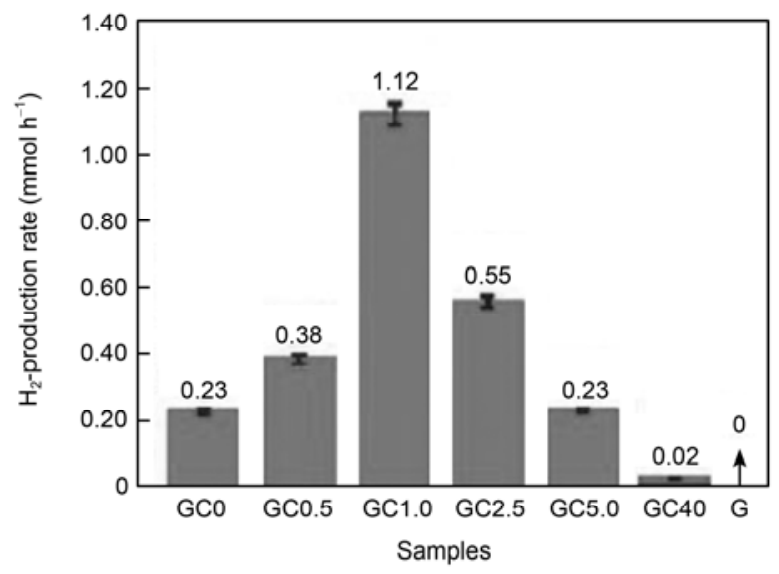

Figure 12 Proposed mechanism for the enhanced electron transfer in the graphene-CdS composites (a) and comparison of the photocatalytic activity of the samples with different contents of graphene (b). Reprinted from ref. [68] with permission from the American Chemical Society. 

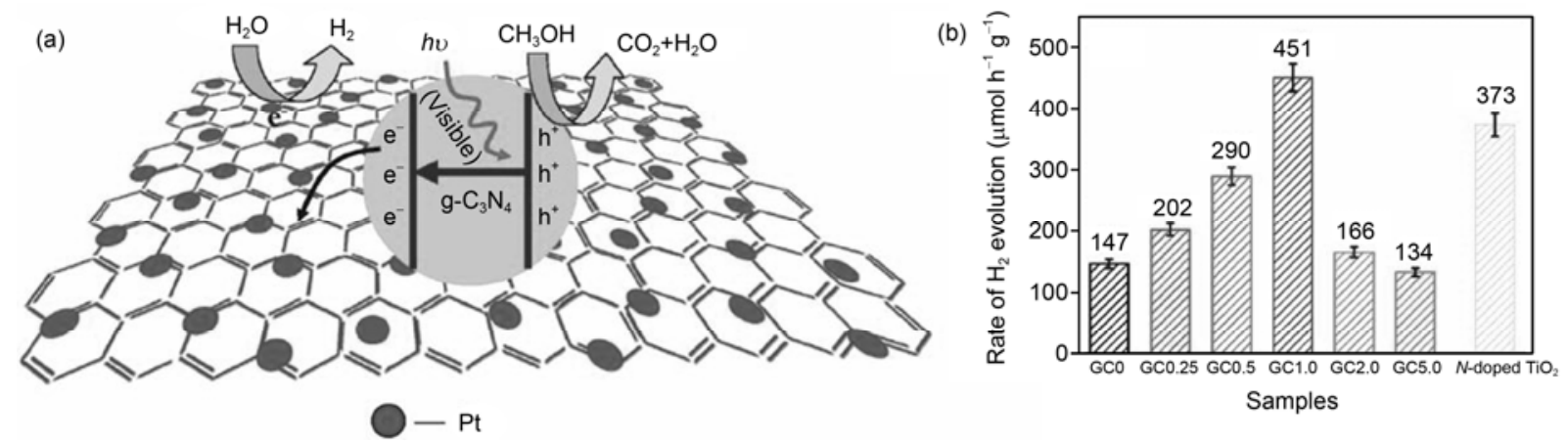

Figure 13 Proposed mechanism for the enhanced electron transfer in the graphene- $g$ - $\mathrm{C}_{3} \mathrm{~N}_{4}$ composites (a) and comparison of the photocatalytic activity of the samples with different content of graphene (b). Reprinted from ref. [70] with permission from the American Chemical Society.

\section{Conclusions}

Graphene, as a 2D material with unique properties, attracts more and more scientists to seek the solutions and answers in various fields. Triggered by the energy and environmental need, graphene-based hybrid materials for energy storage and conversion are widely investigated. In most of the graphene-based hybrid materials, graphene serves as the building block, conductive support, or additive with larger surface area, high flexibility and stability. Although the study of the graphene-based hybrid materials has achieved much progress, there are still many challenges in this field. Further development and study of graphene-based hybrid material in the views of science and technology are still needed to commercialize the application.

In the science view, graphene field developed only for several years, the understanding of graphene in the material and molecule view is limited. Therefore, systematic study of the assembly behavior, interaction and reaction mechanism of graphene/GO is fundamental for the controllable design and fabrication of the high performance graphene-based material. In the technology view, new techniques for the production of graphene in both quality and quantity should be developed. Traditional chemical reduction method for graphene is still not realistic for the commercial production and application. On the basis of the further understanding and proficient technology, graphene-based hybrid material would be a promising candidate for the application in energy storage and conversion fields.

This work was supported by the National Natural Science Foundation of China (91023001) and the Knowledge Innovation Program of Chinese Academy of Sciences (KJCX2-YW-H21).

1 Novoselov K, Geim A, Morozov S, et al. Electric field effect in atomically thin carbon films. Science, 2004, 306: 666-669

2 Compton O, Nguyen S. Graphene oxide, highly reduced graphene oxide, and graphene: Versatile building blocks for carbon-based materials. Small, 2010, 6: 711-723

3 Zhu Y, Murali S, Cai W, et al. Graphene and graphene oxide: Syn- thesis, properties, and applications. Adv Mater, 2010, 22: 3906-3924

4 Sun Y, Wu Q, Shi G. Graphene based new energy materials. Energy Environ Sci, 2011, 4: 1113-1132

5 Wei D, Liu Y. Controllable synthesis of graphene and its applications. Adv Mater, 2010, 22: 3225-3241

6 Dreyer D R, Park S, Bielawski C W, et al. The chemistry of graphene oxide. Chem Soc Rev, 2010, 39: 228-240

7 Loh K P, Bao Q, Ang P K, et al. The chemistry of graphene. J Mater Chem, 2010, 20: 2277-2289

8 Stankovich S, Piner R D, Chen X, et al. Stable aqueous dispersions of graphitic nanoplatelets via the reduction of exfoliated graphite oxide in the presence of poly(sodium 4-styrenesulfonate). J Mater Chem, 2006, 16: 155-158

$9 \mathrm{Xu} \mathrm{Y} \mathrm{X,} \mathrm{Bai} \mathrm{H,} \mathrm{Lu} \mathrm{G} \mathrm{W,} \mathrm{et} \mathrm{al.} \mathrm{Flexible} \mathrm{graphene} \mathrm{films} \mathrm{via} \mathrm{the} \mathrm{filtra-}$ tion of water-soluble noncovalent functionalized graphene sheets. J Am Chem Soc, 2008, 130: 5856-5857

10 Qi X, Pu K Y, Zhou X, et al. Conjugated-polyelectrolyte-functionalized reduced graphene oxide with excellent solubility and stability in polar solvents. Small, 2010, 6: 663-669

11 Liu Z, Robinson J T, Sun X M, et al. PEGylated nanographene oxide for delivery of water-insoluble cancer drugs. J Am Chem Soc, 2008, 130: 10876-10877

12 Wang G X, Wang B, Park J, et al. Synthesis of enhanced hydrophilic and hydrophobic graphene oxide nanosheets by a solvothermal method. Carbon, 2009, 47: 68-72

13 Lomeda J R, Doyle C D, Kosynkin D V, et al. Diazonium functionalization of surfactant-wrapped chemically converted graphene sheets. J Am Chem Soc, 2008, 130: 16201-16206

14 Huang X, Qi X, Boey F, et al. Graphene-based composites. Chem Soc Rev, 2012, 41: 666-686

15 Huang X, Yin Z, Wu S, et al. Graphene-based materials: Synthesis, characterization, properties, and applications. Small, 2011, 7: 18761902

16 Wu Z S, Zhou G, Yin L C, et al. Graphene/metal oxide composite electrode materials for energy storage. Nano Energy, 2012, 1: 107-131

17 Paek S M, Yoo E J, Honma I. Enhanced cyclic performance and lithium storage capacity of $\mathrm{SnO} 2 /$ graphene nanoporous electrodes with three-dimensionally delaminated flexible structure. Nano Lett, 2009, 9: $72-75$

18 Scheuermann G M, Rumi L, Steurer P, et al. Palladium nanoparticles on graphite oxide and its functionalized graphene derivatives as highly active catalysts for the Suzuki-Miyaura coupling reaction. J Am Chem Soc, 2009, 131: 8262-8270

19 Zhou D, Han B H. Graphene-based nanoporous materials assembled by mediation of polyoxometalate nanoparticles. Adv Funct Mater, 2010, 20: 2717-2722

20 Zhang K, Wang H, He X, et al. Hybrid material of vanadium nitride and nitrogen-doped graphene for lithium storage. J Mater Chem, 2011, 21: 11916-11922 
21 Cao A, Liu Z, Chu S, et al. A facile one-step method to produce graphene-CdS quantum dot nanocomposites as promising optoelectronic materials. Adv Mater, 2010, 22: 103-106

22 Choi J, Jin J, Jung I G, et al. SnSe 2 nanoplate-graphene composites as anode materials for lithium ion batteries. Chem Commun, 2011, 47: 5241-5243

23 Lin T, Huang F, Liang J, et al. A facile preparation route for boron-doped graphene, and its CdTe solar cell application. Energy Environ Sci, 2011, 4: 862-865

24 Seng K H, Guo Z P, Chen Z X, et al. SnSb/graphene composite as anode materials for lithium ion batteries. Adv Sci Lett, 2011, 4: $18-23$

25 Zhou D, Cheng Q Y, Han B H. Solvothermal synthesis of homogeneous graphene dispersion with high concentration. Carbon, 2011, 49: 3920-3927

26 Tang Z, Shen S, Zhuang J, et al. Noble-metal-promoted three-dimensional macroassembly of single-layered graphene oxide. Angew Chem Int Ed, 2010, 49: 4603-4607

27 Zhang D D, Zu S Z, Han B H. Inorganic-organic hybrid porous materials based on graphite oxide sheets. Carbon, 2009, 47: 2993-3000

28 Jahan M, Bao Q L, Yang J X, et al. Structure-directing role of graphene in the synthesis of metal-organic framework nanowire. J Am Chem Soc, 2010, 132: 14487-14495

29 Gao Y, Liu L Q, Zu S Z, et al. The effect of interlayer adhesion on the mechanical behaviors of macroscopic graphene oxide papers. ACS Nano, 2011, 5: 2134-2141

$30 \mathrm{Zu} \mathrm{S} \mathrm{Z,} \mathrm{Han} \mathrm{B} \mathrm{H.} \mathrm{Aqueous} \mathrm{dispersion} \mathrm{of} \mathrm{graphene} \mathrm{sheets} \mathrm{stabilized}$ by pluronic copolymers: Formation of supramolecular hydrogel. J Phys Chem C, 2009, 113: 13651-13657

31 Zhang L L, Zhao X S. Carbon-based materials as supercapacitor electrodes. Chem Soc Rev, 2009, 38: 2520-2531

32 Pumera M. Graphene-based nanomaterials and their electrochemistry. Chem Soc Rev, 2010, 39: 4146-4157

33 Chen D, Tang L, Li J. Graphene-based materials in electrochemistry. Chem Soc Rev, 2010, 39: 3157-3180

34 Arico A S, Bruce P, Scrosati B, et al. Nanostructured materials for advanced energy conversion and storage devices. Nat Mater, 2005, 4: 366-377

$35 \mathrm{Wu}$ Q, Xu Y X, Yao Z Y, et al. Supercapacitors based on flexible graphene/polyaniline nanofiber composite films. ACS Nano, 2010, 4: 1963-1970

36 Xu J, Wang K, Zu S Z, et al. Hierarchical nanocomposites of polyaniline nanowire arrays on graphene oxide sheets with synergistic effect for energy storage. ACS Nano, 2010, 4: 5019-5026

37 Mini P A, Balakrishnan A, Nair S V, et al. Highly super capacitive electrodes made of graphene/poly(pyrrole). Chem Commun, 2011, 47: 5753-5755

38 Yan J, Wei T, Fan Z, et al. Preparation of graphene nanosheet/carbon nanotube/polyaniline composite as electrode material for supercapacitors. J Power Sources, 2010, 195: 3041-3045

39 Zhang J, Jiang J, Li H, et al. A high-performance asymmetric supercapacitor fabricated with graphene-based electrodes. Energy Environ Sci, 2011, 4: 4009-4015

40 Wu Z S, Wang D W, Ren W, et al. Anchoring hydrous $\mathrm{RuO}_{2}$ on graphene sheets for high-performance electrochemical capacitors. Adv Funct Mater, 2010, 20: 3595-3602

41 Yan J, Fan Z, Wei T, et al. Fast and reversible surface redox reaction of graphene- $\mathrm{MnO}_{2}$ composites as supercapacitor electrodes. Carbon, 2010, 48: 3825-3833

42 Wang $\mathrm{H} \mathrm{L}$, Casalongue $\mathrm{H} \mathrm{S}$, Liang $\mathrm{Y}$, et al. $\mathrm{Ni}(\mathrm{OH})_{2}$ nanoplates grown on graphene as advanced electrochemical pseudocapacitor materials. J Am Chem Soc, 2010, 132: 7472-7477

43 Wang Y, Cao G. Developments in nanostructured cathode materials for high-performance lithium-ion batteries. Adv Mater, 2008, 20: 2251-2269

44 Brownson D A C, Banks C E. Graphene electrochemistry: An overview of potential applications. Analyst, 2010, 135: 2768-2778

45 Su L, Jing Y, Zhou Z. Li ion battery materials with core-shell nanostructures. Nanoscale, 2011, 3: 3967-3983

$46 \mathrm{Wu}$ D, Li Y, Zhou Z. First-principles studies on doped graphene as anode materials in lithium-ion batteries. Theor Chem Acc, 2011, 130: 209-213

47 Yoo E, Kim J, Hosono E, et al. Large reversible Li storage of graphene nanosheet families for use in rechargeable lithium ion batteries. Nano Lett, 2008, 8: 2277-2282

48 Ding Y, Jiang Y, Xu F, et al. Preparation of nano-structured $\mathrm{LiFePO}_{4} /$ graphene composites by co-precipitation method. Electrochem Commun, 2010, 12: 10-13

49 Guo C X, Wang M, Chen T, et al. A hierarchically nanostructured composite of $\mathrm{MnO}_{2}$ /conjugated polymer/graphene for high-performance lithium ion batteries. Adv Energy Mater, 2011, 1: 736-741

50 Jiang D E, Cooper V R, Dai S. Porous graphene as the ultimate membrane for gas separation. Nano Lett, 2009, 9: 4019-4024

51 Li Y, Zhou Z, Shen P, et al. Two-dimensional polyphenylene: Experimentally available porous graphene as a hydrogen purification membrane. Chem Commun, 2010, 46: 3672-3674

52 Du A, Zhu Z, Smith S C. Multifunctional porous graphene for nanoelectronics and hydrogen storage: New properties revealed by first principle calculations. J Am Chem Soc, 2010, 132: 2876-2877

53 Zhou D, Liu Q, Cheng Q Y, et al. Graphene-manganese oxide hybrid porous material and its application in carbon dioxide adsorption. Chin Sci Bull, 2012, doi: 10.1007/s11434-012-5158-3

54 Srinivas G, Burress J W, Ford J, et al. Porous graphene oxide frameworks: Synthesis and gas sorption properties. J Mater Chem, 2011, 21: 11323-11329

55 Yin Z, Wu S, Zhou X, et al. Electrochemical deposition of $\mathrm{ZnO}$ nanorods on transparent reduced graphene oxide electrodes for hybrid solar cells. Small, 2010, 6: 307-312

56 Wang Y, Tong S W, Xu X F, et al. Interface engineering of layer-bylayer stacked graphene anodes for high-performance organic solar cells. Adv Mater, 2011, 23: 1514-1518

57 Yang N L, Zhai J, Wang S, et al. Two-dimensional graphene bridges enhanced photoinduced charge transport in dye-sensitized solar cells. ACS Nano, 2010, 4: 887-894

58 Li S, Luo Y, Lv W, et al. Vertically aligned carbon nanotubes grown on graphene paper as electrodes in lithium-ion batteries and dye-sensitized solar cells. Adv Energy Mater, 2011, 1: 486-490

59 Kauffman D R, Star A. Graphene versus carbon nanotubes for chemical sensor and fuel cell applications. Analyst, 2010, 135: 2790-2797

60 Saner B, Okyay F, Yürüm Y. Utilization of multiple graphene layers in fuel cells. 1. An improved technique for the exfoliation of graphene-based nanosheets from graphite. Fuel, 2010, 89: 1903-1910

61 Saner B, Dinç F, Yürüm Y. Utilization of multiple graphene nanosheets in fuel cells. 2. The effect of oxidation process on the characteristics of graphene nanosheets. Fuel, 2011, 90: 2609-2616

62 Qiu J D, Wang G C, Liang R P, et al. Controllable deposition of platinum nanoparticles on graphene as an electrocatalyst for direct methanol fuel cells. J Phys Chem C, 2011, 115: 15639-15645

63 Jha N, Jafri R I, Rajalakshmi N, et al. Graphene-multi walled carbon nanotube hybrid electrocatalyst support material for direct methanol fuel cell. Int J Hydrogen Energy, 2011, 36: 7284-7290

64 Lee S H, Kakati N, Jee S H, et al. Hydrothermal synthesis of PtRu nanoparticles supported on graphene sheets for methanol oxidation in direct methanol fuel cell. Mater Lett, 2011, 65: 3281-3284

65 Zarrin H, Higgins D, Jun Y, et al. Functionalized graphene oxide nanocomposite membrane for low humidity and high temperature proton exchange membrane fuel cells. J Phys Chem C, 2011, 115: 20774-20781

66 Zhang X Y, Li H P, Cui X L, et al. Graphene/TiO $\mathrm{T}_{2}$ nanocomposites: Synthesis, characterization and application in hydrogen evolution from water photocatalytic splitting. J Mater Chem, 2010, 20: 28012806

67 Jia L, Wang D H, Huang Y X, et al. Highly durable $N$-doped graphene/CdS nanocomposites with enhanced photocatalytic hydrogen evolution from water under visible light irradiation. J Phys Chem C, 2011, 115: 11466-11473 
68 Min S, Lu G. Dye-sensitized reduced graphene oxide photocatalysts for highly efficient visible-light-driven water reduction. J Phys Chem C, 2011, 115: 13938-13945

$69 \mathrm{Li} \mathrm{Q}$, Guo B, Yu J, et al. Highly efficient visible-light-driven photocatalytic hydrogen production of CdS-cluster-decorated graphene nanosheets. J Am Chem Soc, 2011, 133: 10878-10884
70 Wang X, Maeda K, Thomas A, et al. Metal-free polymeric photocatalyst for hydrogen production from water under visible light. Nat Mater, 2009, 8: 76-80

71 Xiang Q, Yu J, Jaroniec M. Preparation and enhanced visible-light photocatalytic $\mathrm{H}_{2}$-production activity of graphene/ $\mathrm{C}_{3} \mathrm{~N}_{4}$ composites. $\mathrm{J}$ Phys Chem C, 2011, 115: 7355-7363

Open Access This article is distributed under the terms of the Creative Commons Attribution License which permits any use, distribution, and reproduction in any medium, provided the original author(s) and source are credited. 